\title{
Inspiring the next generation of physician-scientists
}

\author{
Robert J. Lefkowitz \\ Howard Hughes Medical Institute, Duke University Medical Center, Departments of Medicine and Biochemistry, Durham, North Carolina, USA.
}

\begin{abstract}
As academic physician-scientists, one of the most important things we do is mentor young trainee-scientists. There obviously is no one right way to mentor or a set of rules one can follow; it's a very personal matter, and very much depends on one's personality. For much of my career, I gave very little thought as to how I mentored my trainees or to whether I was any good at it. Like many investigators, perhaps, I was just too busy with the daily activities of research to consider how I was guiding my students. Here, I take a look back and reflect on my experiences as a mentor and the factors that I believe contribute to the success of trainees as independent scientists.
\end{abstract}

\section{A foundation for success}

I have been fortunate in my career to have mentored well over 200 individuals, and the independent success of so many of these trainees is one of the greatest sources of professional satisfaction that I have. To me, mentoring centers on providing a strong role model, which implies accessibility and transparency to your trainees in as many of your dayto-day activities as possible. In terms of scientific mentorship, this means maintaining enough focus on your research, as opposed to travel or other administrative and clinical activities, to allow you to interact with the fellows and students. A number of years ago, I had the opportunity to celebrate a milestone birthday and hold a reunion with many of my former trainees. This occasion provided a unique forum to hear from my trainees first hand what they felt was most influential about their experience training in my lab.

Overwhelmingly, the most important issue for most of them seems to have been my modeling of an intense, enthusiastic engagement with the day-to-day activities of the scientific life. In my own experience, this style might best be described as a moment-to-moment involvement in activities, characterized by intense, passionate engagement and a sense of timelessness, in which the hours just seem to fly by. Engaged in this way, the ultimate scientific success has often seemed to me as if it were just a byproduct of the central process of doing the work and sharing the experience.

An important element in this type of interaction is the simple power of belief in what you are doing and of its importance. The handmaidens of this belief are enthusiasm and a sense of optimism. The wellspring for this engagement is a keenly felt sense of wonder and curiosity for even the faintest glimpses of new understanding. The word enthusiasm is derived from the Greek and literally means "a god within." And so it is, since true enthusiasm for what we do - a real passion for new knowledge - is a very empowering trait. It confers the ability, or rather the willingness, to tackle difficult and challenging problems. Moreover, it is extremely infectious and likely to be contracted by most people around you, many of whom then become focused on the same problems with which you are engaged; but true enthusiasm can't be faked.

\section{A long lucky streak}

I have learned that I convey to the people around me a sense that I'm very lucky and that this luck will somehow be transferred to them. When they ask why I am so lucky, I tell them that I'm lucky because I believe

Conflict of interest: Robert J. Lefkowitz is a consultant for Five Prime Therapeutics and Lexicon Pharmaceuticals and holds equity in Five Prime Therapeutics, Roche Holding, and Lexicon Pharmaceuticals. Reference information: / Clin Invest. 2015;125(8):2905-2907. doi:10.1172/JCI83222.

that I'm lucky. We all know that serendipity is one of the strongest forces supporting the process of scientific discovery. In a sense, it's the favoring wind at our backs, pushing us forward. But some seem to have real difficulty feeling it. I try to show them that the first step is believing that it's there. For some years now, I have sometimes asked postdoctoral candidates during their interviews, "Are you lucky?" The question generally takes them by surprise. You can imagine the range of responses that I get: everything from "Yes, I'm quite lucky" to "No, a black cloud seems to follow me around." With whom do you think I choose to work?

One former fellow commented that, while he was working with me some 30 years ago, I had him absolutely convinced of the overwhelming importance of his project and, moreover, that it was the most important and central project in the lab. Subsequently, in comparing notes with a number of his lab mates, he found that they all believed the same thing about their own projects. They all believed it because I believed it. I always feel that whatever we're working on at the moment is about the most important thing we've done and, moreover, that we're on the verge of cracking some big problem, whatever it happens to be. I don't think you can overestimate the power of this sort of positive belief, which is quite infectious. The sense of passion and excitement this engenders brings out the very best in people and makes the effort a great deal of fun as well.

I think that a good test of whether this approach is operative is whether one can honestly say that work often feels like play or that you feel that you don't really work for a living, as long of course as your boss doesn't share this view. I believe that if we can inculcate this approach in our trainees, we will have provided them with a lifelong gift - one that will empower them to express their fullest potential.

\section{Leading by example}

Another simple but effective way to impact the careers and attitudes of young people is through the power of role modeling. 
For example, every five years I go through a ritual dreaded by all Howard Hughes Medical Institute (HHMI) investigators. The five-year review involves preparation of some written material, followed by an oral presentation to an extremely elite, some would say daunting, review panel, followed by lots of questions. The review determines whether you receive an additional 5-year period of support. There is a significant attrition rate at these reviews, and seniority or even a Nobel Prize is no safeguard at all. With 39 years of service as an HHMI investigator, I've been through this process seven times now. But it never gets any easier. The last time, I prepared for this review with my usual intensity for a number of months. One Saturday afternoon, one of my fellows wandered into my office to find me assembling articles into about a dozen stacks on my sofa. "What are you doing?" he asked. I explained that I was collecting material to read and study as part of my preparation for the review. He and several others subsequently told me what an impact this level of preparation by such a "senior" professor had on them.

Another example of the importance of role modeling involves lecturing. There are probably few professional activities in which most of us engage that better exemplify the sense of "flow" than lecturing about our work. I often find that after a few minutes of getting into my material, an hour can pass in no time at all. For example, at that HHMI review presentation that I mentioned, when my last PowerPoint slide came up, I had a brief moment of panic, thinking that I must have missed a whole group of slides because I was at the end already, and it seemed to have arrived much too quickly. Of course I hadn't, but time flew as I was caught up in the moment.

Perhaps a more striking example of being in the flow and of role modeling is provided by an experience a former graduate student of mine recently reminded me of. Many years ago, I was to give a talk in an advanced graduate course on cell signaling. Promptly at the agreed upon time, I arrived in the classroom and began. I quickly became absorbed in the material and noticed to my great satisfaction that all the students appeared to be taking copious notes. After 5 or 10 minutes, and with me already in full oratorical stride, one of the students raised his hand and interrupted me. "Professor Lefkowitz," he said, "I'm afraid you are in the wrong room." "What are you talking about?" I said. "This is the final exam in Biochemistry," he said, "and I'm the proctor." Stunned, I asked why they had let me go on for as long as I had. His response summed it up: "You were just so into it and so enthusiastic that we hated to spoil it for you." Well it turned out I was in the right room after all, just in the wrong building, an error I quickly corrected. But 20 years later that student still remembered "just how into that lecture I was."

\section{A focused approach}

At some point or other, all of my students and fellows hear my speech about the four keys to success in research. One is focus, two is focus, three is focus, four is... you get the idea. We all know that every experiment you do raises several new questions, most of which are tangential to the main line of inquiry. Young scientists often seem unable to resist these tempting distractions. I find that one of the most important things I can do for them is to teach them how to focus like a laser on their problem, but this requires the constant input of energy on my part.

The situation in some respects reminds me of the microscope I used in medical school. It was really beat up and had been passed down from class to class for who knows how many generations. I remember sitting in my dormitory room in the evenings peering at histology and pathology slides while studying an atlas. I would get the scope in focus, then look away for a few seconds to consult the atlas. By the time I returned to the scope the stage had slipped just enough to lose the focus. Over time I learned how to keep just enough pressure on the fine-tuning knob with my thumb and forefinger to keep the slide in focus while I looked away. In much the same way, I find that if I go out of town for a few days, when I return, several of the fellows will have wandered off course. So I just gently nudge them back, over and over again. When they finally succeed, they begin to realize the power of focus.

A corollary of focus, especially early in a career, is an ability to say "No" to requests for involvement in too many time consuming activities. One of my former trainees told an anecdote about how my mentoring of him in this regard had an unintended consequence. Up until age 60, I always did a rounding stint each year on the general medical service at Duke or the VA. Although one really should not make travel commitments during that month, I invariably had some. Over a period of years I had developed the habit of arranging coverage for those occasional missed days by calling one or another of the several department of medicine faculty who had previously trained with me and asking them to cover. Presumably out of a sense of respect and loyalty, they almost never said no. The most deferential of them wouldn't even ask me to cover them in return, which, of course, I never volunteered to do anyway. Well, this particular former trainee, who at the time was still at Duke, had been particularly generous over the years in this regard. One year, I had occasion to be out of town for an entire week I think, and so I called him. "Bob," he said, "you know I'd love to help as I have on so many occasions in the past, but my grant renewal is due at the end of the week and I just can't do it this time." I wheedled, cajoled, and arm-twisted, but he stood his ground. Finally, obviously frustrated and, of course, feeling guilty, he said, "Bob, you always told us that sometimes you just need to say no." "That's right," I responded, "but not to me!"

\section{A sense of empowerment}

As leaders and mentors, the very essence of what we do is to empower people and to try to bring out the best in them. My own approach to this has several elements. First, I explicitly tell them early on that my goal is that at some point during their time with me they will experience a sense that they are truly working at their highest possible level. Second, taking a lesson from basketball coaches like Coach Krzyzewski at Duke, I always try to work with whatever gifts my students possess and to develop these rather than trying to shoehorn them into some preconceived mold. Third, I try to steer a delicate course between dictating exactly what they do and simply letting them run entirely free. I think the key is to gradually give them sufficient independence, so that when success finally comes, there is a deep enough sense of personal intellectual ownership that confidence is built and reinforced. 
The issue of empowerment, of course, is inextricably linked to the power of belief. I feel that there is no more empowering force in the mentoring relationship than the strongly felt sense of a trainee that a respected and trusted advisor really believes in their abilities and goals. But this belief must be explicitly communicated to have its magical effects.

Another aspect of empowerment is encouraging creative thinking about problems. I endeavor to do this over time by holding frequent lab meetings in my office. I tend to use liberal doses of humor to encourage out of the box thinking and novel associations. Seeing the joke has elements in common with seeing a previously unappreciated and unexpected association. Somehow it seems that the more I provoke laughter at these meetings, the more creative ideas flow.

Empowerment is also promoted by encouraging not only intellectual courage but technical courage as well. Almost no experimental technique that is learned while in training is still in play by midcareer, so the earlier one learns to adapt new technology to one's problem, the greater the boost to confidence.

Part of my own style is to encourage students to test their ideas rather than overthinking the outcome. Of course I'm being a bit facetious here, but what I'm referring to is the habit of some to critique to death virtually every possible experiment, with all the many reasons why it could never work. Except in obvious cases, I invariably conclude, "let's just do the experiment."

I try to encourage my trainees to have the intellectual courage to challenge conventional wisdom or to take on important problems that seem especially challenging. But I have learned that there is only so much you can do in this regard. You can't change someone's basic personality structure. From time to time, I have been asked by a prospective trainee, "How long does it take for the typical person in your lab to become productive or start producing publishable data?" I'm always surprised by this question, since of course the results are so very variable. But what I tell them is that, if anything, I have observed that the people who go on to the most outstanding careers often are the ones that took longer to initially gain traction in the lab. I think that it may reflect the fact that the most talented scientists are those who by their very nature are bold enough to take on the most important and challenging problems. I've learned that not all people can do this, however, and when one of my trainees turns out to be timid, despite my best efforts to encourage and support a more adventurous tack, I've learned to accept this and work with what I have got.

\section{Telling a meaningful story with data}

A related issue that I try to inculcate in my trainees is the idea of seeing the big picture and building an edifice of work over time. One of my former fellows recalled that I had told him that the basic unit of time in a research career is the decade. What I intended with this comment is the notion of working on big problems over time rather than picking limited opportunistic questions or repeatedly shifting fields. I try to instill the idea that, in the end, each of us is writing a book with many chapters, all hopefully interesting and interrelated, while continuously moving forward toward some worthy longterm conclusions.

In developing that narrative, I've long felt that there is no more important skill for a fledging scientist to develop than that of effective oral and written communication. I think that perhaps some of the nicest compliments that I have received over the years have been those praising the quality of presentations by my fellows and students. Two of my most enjoyable activities to this day are working on manuscripts and talks with my trainees. I try to teach them the elements of clear and effective scientific writing and speaking. It amazes me how many scientists are deficient in this regard. Simple principles, like how to create an interesting title, the difference between an introduction and a discussion, and how to arrange figures to tell a good story, are too often overlooked. Few skills will serve trainees better in their careers than these. But I think they need to be explicitly taught, preferably one-on-one in the course of manuscript preparation.

Finally, some of the most important values that we can inculcate in our trainees are those related to personal integrity and rigor in their science. Of course, the most effective way to transmit these values is through the day-to-day role model- ing we do and the innumerable decisions that we make concerning such things as when to exclude or not exclude data, when to recuse from reviewing a competitor's work, and who to include or exclude from authorship of a paper. At my regular lab meeting, I will from time to time take the opportunity to discuss various issues related to integrity and fraud in science, including some very high-profile retractions of papers with fabricated data. These unfortunate events provide many teachable lessons, and it is important to remind students that falling in love with your theory is dangerous business.

I also stress the importance of replicability of findings by different investigators, even within our own lab. My trainees understand that my request to have one of their findings repeated by one of their lab mates implies no distrust on my part but is just one of the things I do to protect them and myself from reporting procedures that are difficult to replicate.

For more than 40 years now, I've been privileged to enjoy the science, fellowship, friendship, and collegiality of this society. The key to this organization's future, however, clearly lies in our ability to mentor young physician-scientists who share our values and passion. I have no doubt that we're up to the challenge.

\section{About the author}

Robert J. Lefkowitz is the James B. Duke Professor of Medicine at Duke University and a HHMI investigator. He is a member of the National Academy of Sciences, the National Academy of Medicine, and the American Academy of Arts \& Sciences. He was awarded the 2012 Nobel Prize in Chemistry along with one of his former trainees, Brian Kobilka, for their seminal work on $G$ protein-coupled receptors.

\section{Acknowledgments}

R.J. Lefkowitz is an investigator of the HHMI. This work was supported in part by NIH grant HL16037.

Address correspondence to: Robert J. Lefkowitz, Howard Hughes Medical Institute, Duke University Medical Center, Departments of Medicine and Biochemistry, PO Box 3821, Durham, North Carolina 27710, USA. Phone: 919.684.2974; E-mail: lefko001@receptor-biol.duke.edu. 